\title{
Los actos preparatorios de los contratos de préstamo según el Real Decreto legislativo 2/2000, de 16 de junio, por el que se aprueba el texto refundido de la Ley de Contratos de las Administraciones Públicas
}

\author{
M. Pilar Vellisca Matamoros \\ Secretaria de Administración Local
}

Sumario: 1. INTRODUCCIÓN. 2. LOS CONTRATOS SOBRE INSTRUMENTOS FINANCIEROS. SU ENCUADRE EN EL TEXTO REFUNDIDO DE LA LCAP Y CONCORDANCIA CON LA LEY DE HACIENDAS LOCALES. 2.1. Clasificación del contrato. 2.2. Los contratos sobre instrumentos financieros como contratos de Derecho privado. BIBLIOGRAFÍA.

Este trabajo es la plasmación de una inquietud, por mi parte, surgida a raíz de la promulgación de la Ley 13/1995, de Contratos de las Administraciones Públicas y de las sucesivas reformas de la Ley de Haciendas Locales. Y sobre todo de las dificultades que me planteaba la redacción de los informes preceptivos en los expedientes de contratación de préstamos concertados por el Ayuntamiento de Torrevieja (Alicante), en el que tengo mi destino.

Ya en junio de 1997 acudí al Profesor Ruiz Manero, de la Facultad de Derecho de Alicante, que atendió mis dudas y me ayudó a discernir dentro de la maraña interpretativa de los «casos difíciles». No sé si he acertado en la interpretación, pero el hecho de haber realizado actos preparatorios en la contratación de los préstamos, sí ha hecho que mi Ayuntamiento haya obtenido óptimos resultados.

Con ocasión de la reforma de la Ley de Contratos de las Administraciones Públicas por la Ley 53/1999, de 28 de diciembre, he tratado de acomodar dicho trabajo a las nuevas prescripciones legales. $\mathrm{Al}$ igual que se ha hecho con la promulgación del Real Decreto Legislativo 2/2000, de 16 de junio, por el que se aprueba el texto refundido de la Ley de Contratos de las Administraciones Públicas. 


\section{INTRODUCCIÓN}

En la contratación administrativa se dan los requisitos y características de la contratación en sentido estricto. No inventa el Ordenamiento Jurídico administrativo otro núcleo contractual distinto al civil $\mathrm{y}$, por tanto, también existen, necesariamente, el objeto, el consentimiento y la causa.

Lo que sucede es que el negocio contractual avanza con la historia a modelos que aparecen un tanto distorsionados del primer modelo de contrato que el Ordenamiento Jurídico diseñó. Así, no se nos escapa que no es el mismo el concierto de voluntades que existe en quien contrata, mediante un contrato de adhesión, el suministro de energía eléctrica que el que se da en una compraventa. También existe diferencia en la formación del consentimiento entre una persona física y una persona jurídica. Así, aun en el ámbito civil, podemos verificar que el negocio jurídico contractual no es el mismo que hace un siglo, ni medio siglo siquiera.

De igual modo, podríamos concluir que al manifestarse la Administración pública más allá de su función de policía y fomento, y entrar a ser una Administración de servicios, entra en el negocio jurídico contractual una persona jurídica pública, que va a contratar de un modo peculiar. Y la peculiaridad no va a residir en el objeto; sino en el consentimiento y la causa. Regida esa persona jurídica por un Derecho estatutario, como es el Derecho administrativo, va a teñir con sus peculiaridades propias la forma de emitir el consentimiento y la causa en el negocio jurídico contractual. El consentimiento o voluntad lo formará a través de unas normas que confieren poderes ', normas sobre la competencia, y cuyo fin no es otro que el de garantizar la mejor posición jurídica en la realización del negocio jurídico (exigiendo el mejor postor, la mejor calidad, los mejores plazos, etc...). Y en cuanto a la causa, que siempre será la misma, la consecución de los intereses generales, va a existir un estatuto de Derecho público, con técnica legislativa normalmente, que regirán las normas de la voluntad. Y que en aras del fin, el interés general, conseguirán que no decaiga ni una sola de las prerrogativas de la Administración. Aunque esas normas se refieren en un 90 por 100 al tramo preparatorio del contrato, siendo el núcleo de una gran identidad con el negocio jurídico privado.

Ello ha conformado una relación de auxilio a la hora de interpretar, de tal modo que el Ordenamiento Administrativo, hace uso del Civil, para resolver las posibles lagunas en el primero.

\footnotetext{
I En el sentido que lo utilizan Atienza y Ruiz Manero en Las Piezas del Derecho.
} 
Sin entrar ahora en las causas del nacimiento del Derecho administrativo, lo que sí sabemos es que conlleva una distinta forma de entender instituciones jurídicas que estaban en el Ordenamiento Jurídico Civil, Mercantil, etc., precisamente, por el fin que persigue la Administración y por los caudales públicos que maneja. Y no sólo ha tenido distintos tintes en los elementos que tienen las instituciones jurídicas, sino que sus actuaciones son enjuiciadas judicialmente por una jurisdicción que, sin ser especial, sí es especializada, en concreto, la Contencioso-administrativa. Y quizás ello lleva a autores como GARCíA DE ENTERRÍA y Tomás Ramón FERNÁNDEZ, a decir que la distinción entre contrato administrativo-contrato privado es, pues, exclusivamente en su origen, una distinción a efectos jurisdiccionales y no sustantivos.

El artículo 4 del RDL 2/2000, por el que se aprueba el Texto Refundido de la Ley de Contratos de las Administraciones Públicas, recoge la posibilidad de que la Administración pueda concertar cualquier contrato, siempre que no sea contrario al Ordenamiento Jurídico, al interés público o a los principios de buena administración y sin perjuicio de las prerrogativas contempladas en la legislación básica establecidas a favor de la Administración.

Ello hace pensar que siempre habrá unas normas en la preparación del contrato que velen por la adecuada formación de la voluntad de los órganos, mediante un procedimiento establecido al efecto, un procedimiento que constriña a la Administración a exigir que tengan capacidad jurídica y de obrar los que contraten con ella. Y por otra parte, y dado el fin que persigue, no podrá la Administración perseguir un interés de lucro, y deberá, en función del principio de igualdad, someter sus contratos a pública licitación. Dichos principios emanan a su vez del artículo 103 de la Constitución española de 1978.

Por ello, es necesario hacer un análisis del artículo 3 del Texto Refundido de la LCAP, para verificar, que cuando la Ley 13/1995, y la reforma actual por Ley 53/1999, de 28 de diciembre, excluye del ámbito de esta Ley determinados contratos que realiza la Administración, no es para darle una absoluta discrecionalidad en el cómo y en el con quién se contrata; sino que es porque dichos contratos o convenios están regidos en parte por el Derecho administrativo. Así, y siguiendo al Profesor ClIMENT BARBERÁ ${ }^{2}$, podemos hacer una clasificación del mencionado artículo 3 del Texto Refundido de la LCAP:

${ }^{2}$ Conferencia celebrada en la Diputación de Alicante, 1997, y no publicada. 


\section{CLASIFICACIÓN DE LOS CONTRATOS DE LAS ADMINISTRACIONES PÚBLICAS. CONTRATOS EXCLUIDOS DEL TEXTO REFUNDIDO DE LA LEY DE CONTRATOS DE LAS ADMINISTRACIONES PÚBLICAS}

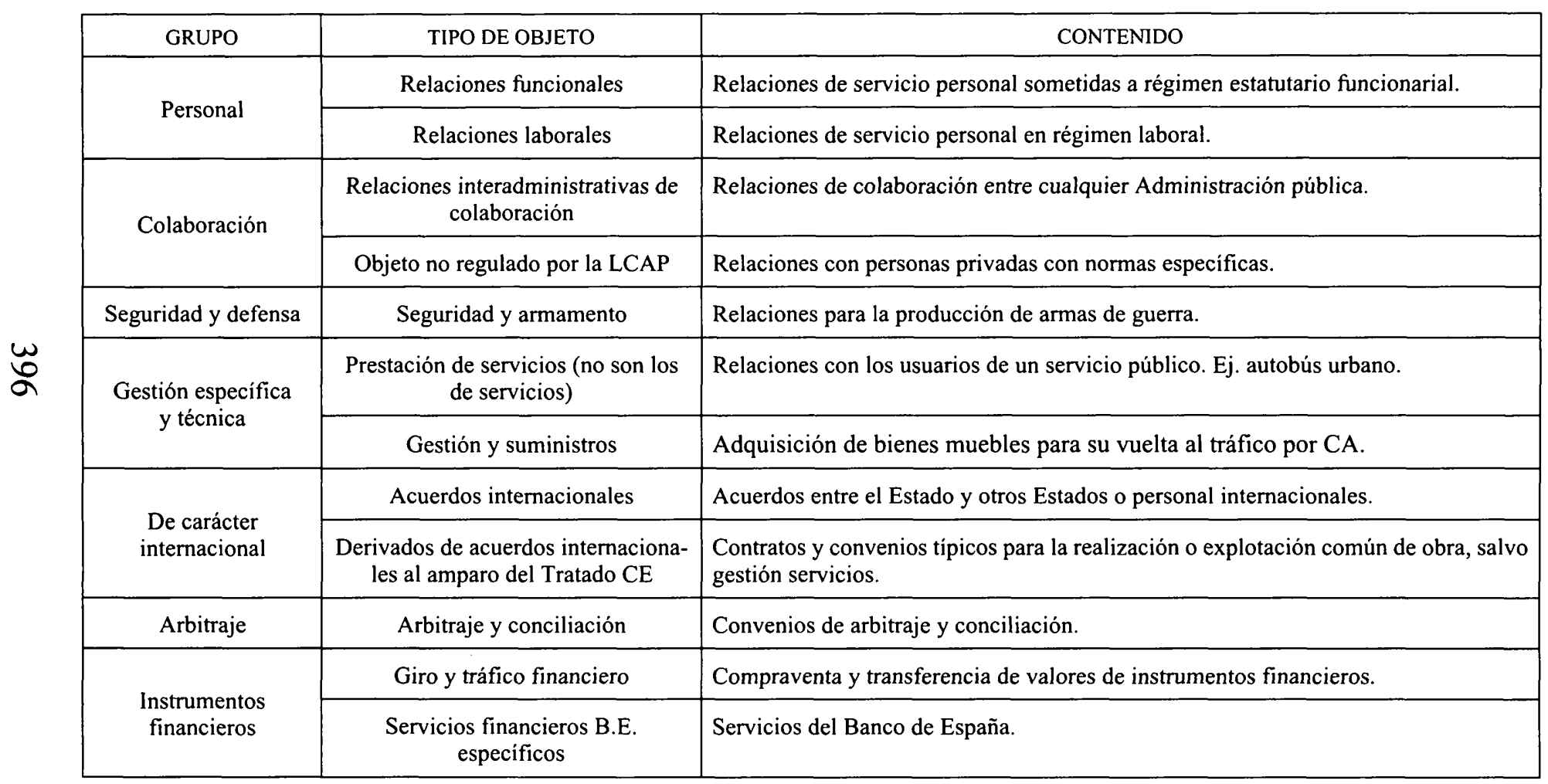


Lógicamente, las relaciones funcionariales, o las laborales que unen a la Administración con el personal a su servicio, no son relaciones que tengan que caer bajo el control de las normas de los actos preparatorios, porque ya tienen un control en su propia formulación y están sujetos a los principios de igualdad (publicación), mérito y capacidad.

También existen, dentro del Derecho administrativo, normas que regulan las relaciones de colaboración entre Administraciones públicas, y entre éstas y particulares, que determinan a su vez, el fin, que es el interés general que la Administración persigue.

En materia de defensa y seguridad de la $\mathrm{CE}$, también resulta lógica la exclusión del Texto Refundido de la LCAP, debido a que hay otra norma con carácter de tratado internacional que los regula.

En cuanto a la prestación de servicios públicos, no parece lógico que se realizasen fases tan complicadas como para celebrar cualquier contrato típico. De modo que resultaría ilógico realizar un pliego de condiciones para que adquiriéramos un billete de autobús. De igual sentido sería concluir la exclusión para los contratos que celebren los organismos autónomos industriales que adquieren bienes para su vuelta al tráfico jurídico, y siempre que los organismos autónomos actúen en ejercicio de competencias específicas atribuidas a ellos por una ley.

Igual suerte parece aplicarse a contratos o convenios que se hayan efectuado por el procedimiento específico de un tratado internacional, o bien cuando el contenido del convenio verse sobre el estacionamiento de tropas. No deja de ser obvio, que aquí la ley que debe regir esas relaciones excede lo contractual y entra en la esfera de lo internacional-público.

Los contratos relativos a arbitraje y conciliación se rigen por las normas de los propios convenios y hacen referencia más a un procedimiento que a normas de contenido sustantivo.

Por último, tenemos los servicios financieros del Banco de España, que se regirán por las normas de los servicios del Banco de España (Circular del Banco de España) y los que son objeto de este trabajo, es decir, los contratos relacionados con los instrumentos financieros, que veremos cómo se ubican dentro del Texto Refundido de la LCAP y qué normas se les aplicará, al estar excluidos de la regulación de esta Ley. 


\section{LOS CONTRATOS SOBRE INSTRUMENTOS FINANCIEROS. SU ENCUADRE EN EL TEXTO REFUNDIDO DE LA LCAP Y CONCORDANCIA CON LA LEY DE HACIENDAS LOCALES}

La Ley de Contratos de las Administraciones Públicas se dicta como aplicación del artículo 149.1.18 de la Constitución, que otorga al Estado competencia exclusiva sobre la materia de legislación básica sobre contratos. Posteriormente se promulga el Texto Refundido para regularizar, aclarar y armonizar los textos legales que han introducido modificaciones en dicha Ley. Su artículo $1 .^{\circ}$ hace referencia a que se aplica a todas las Administraciones públicas, incluida la Local.

Los preceptos del Texto Refundido son básicos unos y otros no.

¿Existe un tercer género fuera del Texto Refundido de la LCAP? ¿Los excluidos en base al artículo 3. ${ }^{\circ}$ ?

El artículo 3.1.k) del Texto Refundido de la Ley de Contratos de las Administraciones Públicas excluye también del ámbito de esta Ley el contrato que contenga cualquier instrumento financiero: «Negocios y contratos excluidos. 1. Quedan fuera del ámbito de la presente Ley: k) Los contratos relacionados con la compraventa y transferencia de valores negociables o de otros instrumentos financieros y los servicios prestados por el Banco de España.»

Y sigue el artículo 3.1.2: «Los supuestos contemplados en el apartado anterior se regularán por sus normas especiales, aplicándose los principios de esta Ley para resolver las dudas y lagunas que pudieran presentarse.»

La Ley 13/1996, de medidas fiscales, administrativas y de orden social, en su artículo 139.4, modificó la redacción del artículo 53 de la Ley 39/1988, de 28 de diciembre, reguladora de las Haciendas Locales, y lo redacta como «1. En la concertación o modificación de toda clase de operaciones de créditos con entidades financieras de cualquier naturaleza, cuya actividad esté sometida a normas de Derecho privado, vinculadas a la gestión del presupuesto en la forma prevista en la sección $1 .^{\mathrm{a}} \mathrm{del}$ capítulo primero del título VI de la Ley 39/1988, de 28 de diciembre, será de aplicación lo previsto en la letra $\mathrm{k}$ ) del artículo 3, apartado uno, de la Ley 13/1995, de 18 de mayo, de Contratos de las Administraciones Públicas. 
En el caso de que no existan previsiones presupuestarias al efecto, será de aplicación, en todo caso, el artículo 9 de la mencionada Ley de Contratos de las Administraciones Públicas, salvo que se realice la oportuna adaptación del presupuesto o de sus bases de ejecución, como condición previa a la viabilidad de los compromisos adquiridos para suscribir la correspondiente operación de crédito. Dicha modificación deberá realizarse por acuerdo del Pleno de la Corporación, en cualquier caso.»

La Directiva europea 92/50 distingue:

— Títulos o valores —deuda pública-.

- Otras variantes financieras.

- Contratos bancarios, no excluidos por el artículo $3 .^{\circ}$ del Texto Refundido de la Ley de Contratos de las Administraciones Públicas.

En mi opinión, están excluidos de las normas del Texto Refundido de la Ley de Contratos, pero lo están porque lo dice el Texto Refundido en su artículo 3, no porque lo mande la Directiva 92/50.

La Directiva no habla más que en sentido negativo: no son contratos públicos de servicios.

Dónde los ubique el Texto Refundido de la Ley de Contratos de las Administraciones Públicas, y qué normas les aplique, salvo lo anterior, no supone un exceso, respecto de la cobertura legal europea.

\subsection{Clasificación del contrato}

¿Qué normas son aplicables a dichos contratos? ¿Cuál es su naturaleza? Intentaré razonar qué son, partiendo de lo que a mi criterio no son, así:

- No son contratos administrativos.

— ¿Pueden ser administrativos especiales?

- Pueden ser contratos de naturaleza privada

Incluidos dentro del artículo 9

Excluidos del artículo 9

Consideremos si son contratos administrativos-especiales. 
Sólo son de naturaleza administrativa, los contratos administrativos típicos [los del art. 5.2.a) y los del art. 5.2.b)]. Y la diferencia entre unos y otros es de mero indicio. Los primeros están claramente especificados, respecto de los segundos. El artículo 5.2.b), dice: «los de objeto distinto a los anteriormente expresados, pero que tengan naturaleza administrativa especial, por resultar vinculados al giro o tráfico específico de la Administración contratante, por satisfacer de forma directa o inmediata una finalidad pública de la específica competencia de aquélla o por declararlo así una Ley».

No parece que la conexión de una Administración local con un contrato de préstamo resulte vinculada al giro o tráfico especializado de la Administración contratante. Tampoco podría decirse que la actividad financiera es una actividad exclusiva de la Administración local.

En el examen de esta cuestión el profesor GARCÍA DE ENTERRÍA, en la obra Ámbito de la aplicación de la ley, comentarios a la Ley de Contratos de las Administraciones Públicas, afirma que «no basta, pues, una relación indirecta o global de la materia contractual con la «específica competencia» de la Administración contratante, sino que se exige una conexión de inmediatez» (sic) (inmediatez). Así lo reitera también el artículo 13 del Texto Refundido de la LCAP.

Se podría afirmar que cuando una Administración local solicita un crédito, no satisface una necesidad que suponga de forma inmediata o directa una finalidad pública; sino que es algo mediático, no es un fin en sí mismo, sino que sirve para hacer algo concreto que sí tiene una finalidad pública en sí misma.

Dentro de la calificación que hace el artículo 5 del Texto Refundido de la Ley de Contratos de las Administraciones Públicas, los contratos que celebre la Administración tendrán (imperativo) carácter administrativo o carácter privado. Parece que no hay lugar a un tercius genus, ya que el término «tendrá» acota las clasificaciones.

El mismo artículo 5 dice cuáles considera administrativos: los de las letras a) y b). Y en su apartado $3 .^{\circ}$, con carácter residual habla de los contratos privados, los restantes.

Si nos fijamos en el contenido del artículo 5.2.b), tiene expresiones tan amplias, que cabría incluir todo lo que hace la Administración en su actividad más reciente. Es decir, la Administración, cada vez más intervencionista en la vida pública, tiene poca actividad que no tenga que ver, 
dentro de sus competencias, con «el giro o tráfico específico de la Administración pública»; o que no «satisfaga una finalidad pública». Toda, o casi toda la actividad de la Administración, tiene una finalidad pública, está destinada a servir el interés general.

Pero esa interpretación es demasiado genérica y demasiado amplia. Parece que sería más adecuado entender que el Texto Refundido se refiere a unos contratos, que sin ser los de la letra a) del artículo 5.2 del citado Texto, tenga una cierta relación con aquellos. Serían «los residuales administrativos». (Vinculados al giro o tráfico jurídico).

Ello unido, a la interpretación, de la Directiva 92/50 CE, habría que concluir, que por la exclusión el artículo 1, a, 7, estos contratos de servicios, los financieros, no son contratos públicos de servicios, luego, si no son públicos, han de ser necesariamente privados, y se han de residenciar en el artículo 5.3 del Texto Refundido de la Ley de Contratos de las Administraciones Públicas.

\subsection{Los contratos sobre instrumentos financieros como contratos de Derecho privado}

Si los ubicamos dentro de los contratos de la Administración, de naturaleza privada (y ello sí es conforme con la directiva, que nunca dice que se hayan de excluir de las normas de preparación y adjudicación para los contratos de las Administraciones públicas de naturaleza privada), hay que volver a analizar dos cuestiones.

$\left.1 .^{\circ}\right)$ Son contratos de naturaleza privada, a los que se les aplica en cuanto a preparación y adjudicación las normas del artículo 9.1 y 2 y los principios del Texto Refundido del artículo 3.2.

O bien,

$\left.2 .^{\circ}\right)$ Son contratos de naturaleza privada, pero excluidos por vía del artículo 3.1.k) del Texto Refundido de la Ley de Contratos de las Administraciones Públicas, y que por no tener normas especiales aplicables, se les aplica analógicamente esta norma, por virtud del artículo 3.2 del Texto Refundido de la Ley de Contratos de las Administraciones Públicas.

Examinaremos la primera cuestión. ¿Son o no aplicables las normas del artículo 9.1 y 2 de la Ley de Contratos de las Administraciones Públicas y los principios legales del artículo 3.2 de la misma Ley? 
«Artículo 9. Régimen jurídico de los contratos privados.

1. Los contratos privados de las Administraciones Públicas se regirán en cuanto a su preparación y adjudicación, en defecto de normas administrativas específicas, por la presente Ley y sus disposiciones de desarrollo y en cuanto a sus efectos y extinción, por las normas de Derecho privado. Los contratos de compraventa, donación, permuta, arrendamiento y demás negocios jurídicos análogos sobre bienes inmuebles, propiedades incorporales y valores negociables se regirán por la legislación patrimonial de las Administraciones Públicas aplicable a cada caso.

2. Los contratos comprendidos en la categoría 6 del artículo 206 referente a contratos de seguros y bancarios y de inversiones $\mathrm{y}$, de los comprendidos en la categoría 26 del mismo artículo, los contratos que tengan por objeto la creación e interpretación artística y literaria y los de espectáculos, se adjudicarán conforme a las normas contenidas en los capítulos II y III del Título IV, Libro II, de esta Ley.

3. El orden jurisdiccional civil será el competente para resolver las controversias que surjan entre las partes de los contratos privados. No obstante, se considerarán actos jurídicos separables los que se dicten en relación con la preparación y adjudicación del contrato y, en consecuencia, podrán ser impugnados ante el orden jurisdiccional contencioso-administrativo de acuerdo con la normativa reguladora de dicha jurisdicción.»

Cuando el artículo 9 se refiere a la aplicabilidad de las normas de preparación y adjudicación de los contratos privados, hay que tener en cuenta su carácter básico.

Cuando el artículo 9.1, último párrafo, dice que determinados contratos se regirán por las normas patrimoniales de la Administración, aplicables a cada caso, no incluye a los contratos de instrumentos financieros. Parece que en buena técnica interpretativa, sería correcto afirmar que dichos contratos de naturaleza privada, sí necesitan de unos actos separables, enjuiciables en la Jurisdicción Contencioso-Administrativa, para realizar la preparación y adjudicación del contrato.

Si no fuese así, si siempre, desde que se decide realizar el préstamo hasta que se formaliza, no hubiera legislación aplicable, el acto administrativo sería un acto político y no estaría sometido a la ley ni al Derecho, vulnerándose la exigencia del artículo 103 de la Constitución española.

Parecería lógico pensar que existe una remisión en el artículo 9.1 del Texto Refundido de la Ley de Contratos de las Administraciones Públicas y que «sus normas aplicables» son el Código de Comercio. Pero la regulación contenida en la legislación mercantil no exige que se contrate con el mejor banco, ni en la mejor opción. Un particular puede contratar con cual- 
quier banco, aun en las peores condiciones. El Ordenamiento Jurídico privado no tutela el mejor interés, sino la libertad de pacto. No parece que ello pueda predicarse de la actuación de la Administración pública.

Es más bien al contrario. Así, aunque el contenido, naturaleza del contrato, etc..., sea mercantil, se necesita que existan previamente, unos actos, preparatorios, que regidos por el Derecho administrativo, hagan posible la contratación mercantil. Y esos actos han de ser necesariamente administrativos, y residenciable su enjuiciamiento, en vía jurisdiccional contencioso-administrativa.

Lo que sucede, es que esa conclusión, de la necesidad de los actos preparatorios en la contratación de instrumentos financieros no se puede hacer de la literalidad de la Ley (primera norma hermenéutica del Código Civil), sino que hay que hacer una interpretación integradora. Dicha interpretación es la siguiente:

- Todo contrato privado va precedido de actos preparatorios, los actos separables. Artículo 9 del Texto Refundido de la Ley de Contratos de las Administraciones Públicas.

- Esos actos preparatorios se basan, a falta de ley, en los principios de los artículos 103 y 106 de la Constitución española y también en los principios de la norma que los regula, el artículo 3.2 del Texto Refundido de la Ley de Contratos de las Administraciones Públicas.

- Si en este caso, artículo 3.k) del Texto Refundido de la Ley de Contratos de las Administraciones Públicas, excluye a los contratos de préstamo de la aplicación de la misma, lo debe ser sólo entendido en cuanto a sus efectos y extinción, no en cuanto a los actos separables.

- En el Código de Comercio, no están regulados los actos separables, luego, la norma integradora ha de ser el propio Texto Refundido de la Ley de Contratos de las Administraciones Públicas. (También por indicación del art. 3.2 del Texto Refundido de la Ley de Contratos de las Administraciones Públicas).

La razón por la cual se llega a esta conclusión está en consonancia con lo que afirma un sector doctrinal, como GarCÍA DE ENTERRía y PREDIERI, que en la obra La Constitución Española de 1978, Civitas, 1981, en la monografia denominada «El sistema de las fuentes del Derecho», el profesor italiano afirma: que «afrontar la problemática de los principios como fuente del Derecho en la Constitución española implica tener en 
cuenta todo el entramado constitucional». Y sigue diciendo el profesor PREDIERI, que en este entramado de derechos de los que se obtienen los principios generales del Derecho que actúan como fuente del Ordenamiento Jurídico, también se encuentra el artículo 103.1 de la Constitución que «confirma la posición de la Administración Pública como de "sometimiento a la ley y al Derecho", tomada esta fórmula del artículo 20.3 de la Ley Fundamental de Bonn», aunque a diferencia de la Ley alemana, que predica ese sometimiento sólo respecto de la jurisdicción, en nuestra Constitución española, se predica de la Administración, de igual modo.

Todo ello lleva a concluir que la aplicación del artículo 103.1 de la Constitución española, supone buscar la norma que integre los "actos preparatorios del contrato», los actos separables. Creo lo más lógico, y jurídicamente más aceptable, recurrir al artículo 9 del Texto Refundido de la Ley de Contratos de las Administraciones Públicas.

No es posible «inventar» un procedimiento de publicidad y concurrencia por cada operador jurídico de cada Administración pública, cuando existe un procedimiento establecido por la ley para todos ellos, precisamente en el Texto Refundido de la Ley de Contratos de las Administraciones Públicas y con carácter de básico (art. 9.2 del Texto Refundido de la LCAP). Además, las normas de procedimiento son de Derecho necesario.

Tampoco sería lógico entender que los principios de publicidad y concurrencia se cumplimentan con la publicidad dada a los Presupuestos de los Entes Locales. Ya que chocaríamos con los principios de seguridad jurídica para determinar cuándo se abren o cierran plazos, condiciones a las que se les da mayor o menor relevancia, etc...

Argumento al que nos llevará la conclusión de la siguiente cuestión, pero por razonamiento totalmente distinto.

Segunda cuestión. ¿Se puede entender que son contratos excluidos del Texto Refundido de la Ley de Contratos de las Administraciones Públicas? Parece que sí. Así lo dice el artículo 3.1.k).

¿Cuáles son las normas aplicables a dicho contrato, en cuanto a su preparación y adjudicación? (Dejando a salvo lo dicho anteriormente, se puede llegar a las siguientes argumentaciones).

El artículo 3.2 dice que los supuestos contemplados anteriormente se regularán por sus normas especiales, aplicándoles los principios de esta Ley para resolver las dudas y lagunas que pudieran plantearse. 
¿Cuáles son las normas especiales aplicables a la concertación de préstamos en las Entidades Locales?

Hay dos opciones:

- Las normas del Código de Comercio. Sobre la opinión que éstas merecen, en lo no referido al contenido y extinción del contrato, es necesario remitirse a lo que se acaba de decir respecto de que estos contratos carecieran de normas administrativas para la preparación y adjudicación de los contratos y hubiera que acudir al Ordenamiento Jurídico Privado.

- El artículo 53 y concordantes de la Ley 39/1988, Reguladora de las Haciendas Locales.

Hay quienes afirman que es aplicable el artículo 53 de la Ley 39/1988, de 28 de diciembre, Reguladora de las Haciendas Locales, en la nueva redacción dada por la Ley 13/1996, de medidas fiscales, administrativas y sociales, dice así:

«1. En la concertación o modificación de toda clase de operaciones de créditos con entidades financieras de cualquier naturaleza, cuya actividad esté sometida a normas de Derecho privado, vinculadas a la gestión del presupuesto en la forma prevista en la sección $1 .^{a}$ del capítulo primero del título VI de la Ley $39 / 1988$, de 28 de diciembre, será de aplicación lo previsto en la letra k) del artículo 3, apartado uno, de la Ley 13/1995, de 18 de mayo, de Contratos de las Administraciones Públicas.

En el caso de que no existan previsiones presupuestarias al efecto, será de aplicación, en todo caso, el artículo 9 de la mencionada Ley de Contratos de las Administraciones Públicas, salvo que se realice la oportuna adaptación del Presupuesto o de sus bases de ejecución, como condición previa a la viabilidad de los compromisos adquiridos para suscribir la correspondiente operación de crédito. Dicha modificación deberá realizarse por acuerdo del Pleno de la Corporación, en cualquier caso.»

En este artículo se cita la Ley de Contratos de las Administraciones Públicas, pero, tras la entrada en vigor del Real Decreto Legislativo $2 / 2000$, de 16 de junio, por el que se aprueba el texto refundido de la citada Ley, habremos de citar este último texto legal.

El artículo 53, anteriormente transcrito, dice que al concertar o modificar una operación de crédito, cuyo objeto esté vinculado a la gestión del Presupuesto, según está regulado en la Ley 39/1988, Reguladora de las Haciendas Locales, está excluida del Texto Refundido de la Ley de Contratos de las Administraciones Públicas por aplicación del artículo 3.1.k). Nada nuevo añade a lo dicho en el Texto Refundido de la Ley de Contratos de las 
Administraciones Públicas, salvo que los créditos han de ser reconocidos en el estado de ingresos y gastos del Presupuesto, como no podía ser de otra manera. Pero recordemos que, hasta ahora, no hay norma aplicable. El Presupuesto Municipal no es una norma, es un acto administrativo. Y la inclusión de los posibles créditos para financiar obligaciones del Presupuesto, necesariamente han de ser consignados en el Presupuesto. Pero, insisto, por ello no hemos encontrado «su norma especial» aplicable, tal como previene el artículo 3.2 del Texto Refundido de la Ley de Contratos de las Administraciones Públicas. Sólo tenemos un requisito legal de tener que encontrarse el crédito contenido en el estado de ingresos, dentro de los documentos que forman necesariamente, y por ley, parte del Presupuesto, y recogidas las obligaciones que conlleva el crédito, en el estado de gastos. Así, y por imperativo del RD 500/1990, se consignará en una partida del estado de ingresos, la cuantía en la que consistirá el préstamo financiero, para atender a las obligaciones a las que se destina el préstamo. Y en el estado de gastos se consignará en una partida la amortización del préstamo y, en otra, los gastos derivados del pago de intereses.

Pero el artículo 53.1 de la Ley 39/1988, de 28 de diciembre, de Haciendas Locales, $2 .^{\circ}$ párrafo, introduce una serie de acotaciones que no se llegan a entender correctamente, si se unen a otras previsiones de la propia Ley 39/1988, Reguladora de las Haciendas Locales.

Así, dice la nueva redacción del artículo 53 de la Ley 39/1988, de 28 de diciembre, de Haciendas Locales «que en el caso de que no existan previsiones presupuestarias al efecto, será de aplicación, en todo caso, el artículo 9 de la mencionada Ley de Contratos de las Administraciones Públicas, salvo que se realice la oportuna adaptación del Presupuesto o de sus bases de ejecución, como condición previa a la viabilidad de los compromisos adquiridos para suscribir la correspondiente operación de crédito».

¿Qué quiere decir que no haya previsiones presupuestarias al efecto? Si significase que no se han incluido en el estado de gastos y de ingresos, la consecuencia jurídica no puede ser, a la vez, que se aplique el artículo 9 del Texto Refundido de la Ley de Contratos de las Administraciones Públicas y el artículo 154.5. de la Ley Reguladora de las Haciendas Locales. Por cuanto el artículo 9 del Texto Refundido de la Ley de Contratos de las Administraciones Públicas establece un procedimiento para los actos preparatorios y el artículo 154.5 dice que «no podrán adquirirse compromisos de gastos por cuantía superior al importe de los créditos autorizados en los estados de gastos, siendo nulos de pleno derecho los acuerdos, 
resoluciones y actos administrativos que infrinjan la expresada norma, sin perjuicio de las responsabilidades a que haya lugar».

O bien, cabría decir que es posible realizar operaciones de crédito no presupuestados, haciendo una derogación tácita de artículos (y principios de la Ley de Haciendas Locales) y aplicable el artículo 9 del Texto Refundido de la Ley de Contratos de las Administraciones Públicas. O bien que ante la contradicción frontal de dos artículos de la Ley Reguladora de las Haciendas Locales, habría que interpretar que en virtud de que una norma de un bloque normativo especial (Ley 39/1988, de 28 de diciembre, Reguladora de las Haciendas Locales), no puede ser derogado por una norma de igual rango, pero de bloque normativo general (RDL $2 / 2000$, Texto Refundido LCAP), habría que entender que el Texto Refundido de la Ley de Contratos de las Administraciones Públicas tiene mala técnica legislativa.

Pero sigue también diciendo el párrafo que, a pesar de no haber previsión presupuestaria, tampoco se aplicará el artículo 9 del Texto Refundido de la Ley de Contratos de las Administraciones Públicas, cuando se haga la oportuna adaptación del Presupuesto o sus bases de ejecución, como condición previa a la viabilidad de los compromisos adquiridos para suscribir la correspondiente operación de crédito.

Y ello es todavía más difícil de entender. No parece que se pueda decir, en la frase disyuntiva, «adaptación del presupuesto $o$ bases de ejecución del presupuesto», que tanto cabría incluir una operación de crédito en los estados de ingresos y gastos, como incluirlo en las bases de ejecución de Presupuesto. Ello no es predicable, porque en cada documento del Presupuesto se ha de ubicar lo preceptivo, y no es ubicable una operación de crédito en las bases de ejecución del Presupuesto, sino que ha de ser en los estados de ingresos y gastos, respectivamente, el ingreso del instrumento financiero y los gastos que el mismo, lleva aparejados.

Así lo dice el artículo 146.1.a) y b) de la Ley Reguladora de las Haciendas Locales: «El Presupuesto General contendrá para cada uno de los presupuestos que en él se integren:

a) Los estados de gastos, en los que se incluirán, con la debida especificación, los créditos necesarios para atender al cumplimiento de las obligaciones.

b) Los estados de ingresos, en los que figurarán las estimaciones de los distintos recursos económicos a liquidar durante el ejercicio.» 
¿Podría entenderse que la alusión que hace la Ley a las bases de ejecución del Presupuesto significa que se ha de regular alguna reglamentación procedimental en las bases de ejecución del Presupuesto, que sustituya la aplicación del artículo 9 del Texto Refundido de la Ley de Contratos de las Administraciones Públicas?

La Ley Reguladora de las Haciendas Locales dice en su artículo 146.1, párrafo final: «Asimismo, incluirá las Bases de Ejecución, que contendrán la adaptación de las disposiciones generales en materia presupuestaria a la organización y circunstancias de la propia Entidad, así como aquellas otras necesarias para su acertada gestión, estableciendo cuantas prevenciones se consideren oportunas o convenientes para la mejor realización de los gastos y recaudación de los recursos, sin que puedan modificar lo legislado para la administración económica ni comprender preceptos de orden administrativo que requieran legalmente procedimiento y solemnidades específicas distintas de lo previsto para el Presupuesto.»

Cuando hace referencia a que las bases de ejecución del Presupuesto no podrán contener preceptos de orden administrativo que requieran legalmente procedimiento y solemnidades específicas distintas de lo previsto para el presupuesto, es preciso traer a colación varias argumentaciones jurídicas:

1. Lo que afirma el preámbulo de la Ley 30/1992, al hablar del procedimiento, y que es que «como ha señalado la jurisprudencia constitucional, no se puede disociar la norma sustantiva de la norma de procedimiento.»

Es difícil comprender cómo la regulación sustantiva (aunque sea para excluir estos contratos de la Ley de Contratos de las Administraciones Públicas), la haga una norma estatal y el procedimiento (aquí básico), quede a criterio de la regulación de cada Entidad local.

2. Las normas de procedimiento han de ser reguladas por ley o reglamento. La potestad reglamentaria de las Administraciones públicas locales reside en el Pleno, pero su aprobación difiere de la forma de aprobación de los Presupuestos. Así, mientras el Presupuesto, se aprueba, se expone por plazo de 15 días, y se resuelven las alegaciones y se vuelve a publicar. En las Ordenanzas se aprueba, inicialmente, se someten a información pública 30 días y se resuelven las alegaciones y se aprueba definitivamente por el Pleno, con publicación de su texto íntegro en el Boletín Oficial de la Provincia, según la nueva redacción del artículo 70.2, de la Ley 7/1985, dada por la Ley 39/1994, de 30 de diciembre. Por lo cual 
cabe concluir que tienen distinto procedimiento de aprobación el Presupuesto y las Ordenanzas y es distinta la necesidad de publicación (obligatoria para las Ordenanzas, respecto de su texto íntegro) mientras que, para el presupuesto, no se exige más que la publicación de un resumen y publicidad del resto de su contenido.

El Reglamento municipal por excelencia, donde se deben recoger procedimientos generales, es el Reglamento Orgánico Municipal, y su aprobación exige mayoría absoluta y publicación del texto íntegro (art. 70.2, Ley 7/1985, de 2 de abril, Reguladora de las Bases de Régimen Local). A diferencia de la mayoría simple que exige el Presupuesto.

3. Si las bases de ejecución del Presupuesto contuvieran normas reglamentarias, habría de ser publicado su texto íntegro, tal y como exige el artículo 70.2 de la Ley $7 / 1985$, cosa que en absoluto se exige para dichas bases de ejecución, ni en la Ley 39/1988, Reguladora de las Haciendas Locales, ni en el Real Decreto 500/1990.

4. ${ }^{\circ}$ Si con consignar en las bases o en el estado de ingresos y gastos del Presupuesto, la concertación de operaciones financieras, fuera suficiente para poder establecer un contrato con la Administración pública, se estaría o bien obligando a la aprobación del Presupuesto por mayoría absoluta, cuando dichas operaciones supusieran una cuantía superior al 5 por 100 de los Recursos Ordinarios del Presupuesto, o bien habría que entender también derogado tácitamente el artículo 47 de la Ley Reguladora de las Bases del Régimen Local, y poderse concertar dichas operaciones por mayoría simple.

Por todo ello, no parece que las normas especiales de la concertación de operaciones financieras en las Administraciones locales sean las del artículo 53.1 de la Ley Reguladora de las Haciendas Locales, porque dicha interpretación conduciría al absurdo y contravendría varias normas de Administración Local, desde la Ley Reguladora de las Bases del Régimen Local, hasta la propia Ley Reguladora de las Haciendas Locales.

Y si el artículo 53.1 de la Ley Reguladora de las Haciendas Locales no es aplicable, porque crea más problemas que soluciones, nada impediría concluir que, ante las dudas y lagunas que plantea, entrara en juego lo prevenido en el mencionado artículo 3.2 del Texto Refundido de la Ley de Contratos de las Administraciones Públicas.

Y entrando en relación este artículo tendríamos que buscar la ley aplicable analógicamente e incluso los principios generales del Derecho. 
Habría que buscar qué normas son las más acordes con este tipo de contratos en cuanto a su preparación y dichos actos serán enjuiciables en la vía contencioso-administrativa, no pudiendo sustraerse estos actos a las prohibiciones de contratar del artículo 20 y a los requisitos de capacidad y solvencia del Capítulo I, Título II y el Capítulo II del Texto Refundido de la LCAP.

De tal modo, es necesario verificar los requisitos que la Ley contiene en esos preceptos, que la detección de vicios en esa fase conllevaría aparejada la sanción de la nulidad en la contratación.

Pero no terminan aquí las dudas que plantean los contratos financieros. Cuando la Ley 13/1996, en su artículo 139.4), modifica el 53 de la Ley 39/1988, de Haciendas Locales, en el último párrafo del apartado 1, dice «en caso de no existir previsiones presupuestarias al efecto, será de aplicación el artículo 9 de la mencionada Ley de Contratos...», podemos entender que incluye a las operaciones de tesorería - reguladas en los arts. 52 y 53 de la Ley 39/1988, de Haciendas Locales - que son operaciones extrapresupuestarias. Entonces, ¿cabe colegir que aquí, directamente, la Ley rehúsa buscar otras normas aplicables y reenvía directamente a las normas preparatorias de los contratos privados del artículo 9 del Texto Refundido de la LCAP?, y si ello es así, cuál es el fundamento jurídico, lógico y armónico que preside esta Ley. ¿Entiende que es el Presupuesto de las Entidades Locales el lugar donde se conforma el procedimiento, a pesar de las contradicciones de mayorías para la formación de la voluntad del órgano, según se refieran a cantidades menores del 5 por 100 de los recursos ordinarios del Presupuesto y a la interdicción del artículo 146 de la Ley de Haciendas Locales, ya referido arriba?

Por otro lado, la Directiva europea 50/92, en el artículo 7.a)iii), entiende que sí son contratos públicos de servicios: los contratos de servicios financieros celebrados bien al mismo tiempo, bien con anterioridad o posterioridad al contrato de adquisición o arrendamiento, en cualquiera de sus formas, de terrenos, edificios ya existentes u otros bienes inmuebles relativos a derechos de estos bienes.

Dicha reseña no ha tenido cabida expresa en la Ley 13/1995, de Contratos de las Administraciones Públicas, ni en la reforma de la Ley 13/1996. No lo recoge el Texto Refundido de la Ley de Contratos, RDL $2 / 2000$, de 16 de junio, por no ser el instrumento jurídico adecuado. Mal puede innovar un Texto Refundido lo que no contiene la Ley.

Por lo cual, a mi juicio, queda determinada como privada la naturaleza de los contratos financieros que celebran las Entidades Locales. Su conte- 
nido y extinción se regirá por las normas del Código de Comercio. Sus actos preparatorios, y por vía interpretativa lógica y sistemática, han de ser los que establece el artículo 9 del Texto Refundido de la LCAP y los principios generales del Derecho, en las lagunas que existieran. Y sólo con la salvedad de los contratos financieros recogidos en la Directiva europea 50/92, artículo $7 . a)$ iii).

Las fundamentaciones jurídicas de interpretación que a continuación resumo, son o intentan, al menos, ser la explicación sistemática y lógica de las conclusiones de mi trabajo.

Al no tener otra «capacidad» en el sistema jurídico que la de operadores jurídicos, y por ello, vamos abocados a la aplicación del Derecho dado, no queda otra solución que explicar en qué se basa la actuación interpretativa de las normas que nos son dadas. Otra cosa distinta es que se pudiera solicitar del legislador la aclaración de su intención, o la derogación expresa de lo que produce antinomias y lagunas.

La conclusión a que he llegado obedece a una argumentación jurídica basada en unos criterios interpretativos, que dejaré reseñados, porque son el iter adecuado para llegar a una conclusión acertada, en lo que los autores llaman «casos difíciles».

Cuando el Texto Refundido de la Ley de Contratos de las Administraciones públicas reseña que quedan fuera del ámbito de la Ley de Contratos de las Administración Pública los instrumentos financieros crea una laguna, no en cuanto a la naturaleza de los contratos, que al no ser administrativa es privada; sino en cuanto a los actos preparatorios aplicables al contrato de naturaleza privada (ya que en la contratación no existe un tercer género).

Sabemos, que ALCHOURRÓN y BULYGIN definieron las lagunas normativas como «un cierto caso... de un determinado sistema normativo, en el que éste sistema no correlaciona el caso con alguna calificación normativa de determinada conducta» (o sea, con una solución).

Respecto a las lagunas del Derecho, ha habido autores, como $\mathrm{H}$. KELSEN, que sostienen que éstas no deben existir dentro del Ordenamiento Jurídico, ya que éste tiene vocación de cerrar las soluciones, estableciendo un principio, llamado de clausura, cuyo contenido es que «todo lo que no está prohibido, está permitido».

Siguiendo esta solución de clausura se podría concluir que si no está prohibido contratar prescindiendo de los actos preparatorios, es que está permitido. 
Lo primero que hay que dejar claro es que ese principio kelseniano en la resolución de las lagunas, sí es aplicable en Derecho penal o Derecho privado; pero en modo alguno en el Derecho administrativo y ello en virtud de que los principios que rigen esta parte del Ordenamiento Jurídico, persiguen otros fines.

Veamos qué son los principios. Siguiendo a M. ATIENZA y a J. RUIZ MANERO, los principios (explícitos o implícitos) sirven para resolver el caso, al igual que sirven las reglas. Los principios explícitos son razones para la acción independientes del contenido (por razón de su origen. Por ejemplo, contenidos en la Constitución de 1978), pero no perentorios. Y siguen diciendo los autores, que no son perentorios, porque no están destinados a excluir de la deliberación, de quien interpreta, acerca del contenido de la resolución a dictar, sino que ha de ser ponderada por el intérprete, respecto de otras razones para resolver en un sentido o en otro.

Así, el artículo 103.1 de la Constitución española, al decir que «La Administración Pública sirve con objetividad los intereses generales y actúa de acuerdo con los principios de eficacia, jerarquía, descentralización, desconcentración y coordinación, con sometimiento pleno a la ley y al Derecho», supone la confirmación de un principio explícito. No es posible, por un lado, que una normativa de carácter secundario, la contradiga, y hay que valorar con qué normas se consiguen los fines que persigue, es decir, obliga al intérprete a valorar con qué reglas se logra el objetivo al que su contenido va dirigido. El carácter de este principio del Derecho del artículo 103 de la Constitución española representa, en sentido fuerte, la invalidez de una norma - regla - que la contradiga; y en sentido débil, del pronunciamiento de inconstitucionalidad de la norma, eso sí, tras el proceso judicial adecuado.

Para el correcto cumplimiento de lo preceptuado en el artículo 103 de la Constitución, hemos de acudir, en el caso que nos ocupa, a la interpretación normativa. La integración de las lagunas nos lleva a buscar una norma que sirva para supuestos idénticos. Nos podríamos preguntar si para alcanzar los intereses generales en materia de contratación privada, la Administración usa algún procedimiento que sea objetivo, eficaz y con sometimiento a la ley y al Derecho. Y la respuesta es clave: son los actos preparatorios, los actos administrativos, que suponen igualdad para los licitadores, capacidad suficiente para contratar con la Administración, garantías y unas óptimas condiciones en la licitación. Luego, hemos soslayado la existencia de las lagunas respecto de los contratos sobre instrumentos financieros, ante lo que el Texto Refundido de la Ley de Contratos de las Administraciones Públicas, llama «exclusión de esta Ley». 
El mayor probiema, no obstante, se encuentra en argumentar que ei artículo 53 de la Ley de Haciendas Locales no es la norma administrativa especial de las que habla el artículo 3.2 del Texto Refundido de la Ley de Contratos de las Administraciones Públicas, para regir los contratos de los intrumentos financieros, con preferencia sobre el artículo 9 del Texto Refundido de la LCAP. Y la dificultad se encuentra que al ser una regla, no da lugar a que el intérprete haga una valoración sobre si es o no aplicable, ya que, como los profesores ATIENZA y RUIZ MANERO proponen, estas reglas están destinadas a que si se dan sus condiciones de aplicación, quien aplica la norma, excluye su propio juicio acerca del balance de razones jurídicas aplicables y se adopta como base la solución, aquello que la regla contiene como tal.

Ello no plantearía problema alguno, si la solución en que se subsume el hecho no contraviniere frontalmente el contenido de otra norma. Lo que se denomina antinomia. Y que la contravención no sea respecto de una norma de bloque normativo distinto, sino que contraviene de forma radical normas que están en el mismo cuerpo normativo, en la Ley de Haciendas Locales, e incluso en la Ley Reguladora de Bases de Régimen Local.

En este caso, en lugar de ausencia de legislación, lo que existe es una multitud de soluciones al mismo tema, pero contradictorias entre sí. A esta situación NINO le llama inoperancia de las normas jurídicas, y se produce si una norma pugna con lo dispuesto en otra, de tal modo que ejecutar una acción ordenada en una norma requiere el cumplimiento de una circunstancia prohibida en otra.

Sobre esta situación, la aplicación, por sí sola, de que la Ley Especial se superpone a la Ley General, no es lo más importante o por lo menos no es lo único importante.

La resolución del caso aquí no está construida por la obediencia a razones perentorias, han de buscarse razones contenidas en el propio sistema jurídico. En el decir, de ATIENZA y RUIZ MANERo (Las piezas del Derecho) "puede hablarse así de una deliberación normativamente guiada, que constituye también una forma de obediencia, pero diferente de la obediencia que consiste en el seguimiento de una razón perentoria». 
REALA 283 (MAYO-AGOSTO, 2000)

\section{BIBLIOGRAFÍA}

ALChOURRON-BUlygin, Introducción a la metodología jurídica de las ciencias juridicas y sociales, 1974, Ed. Astrea, Buenos Aires.

AtienZA, Manuel y Ruiz Manero, Juan, Las piezas del Derecho, Ariel, 1996.

CALVo GaRCíA, Manuel, Interpretación y argumentación jurídica (Trabajos Seminario de Metodología Jurídica 1995). Editado en Prensas Universitarias, Zaragoza.

García DE EnTERría y Fernández, Tomás Ramón, Curso de Derecho Administrativo, Civitas, 1995.

KELSEN, Teoría pura del Derecho (traducción al castellano de Roberto J. Vernengo), México, 1982. 